Alphonse de Beauchamp and the History of Brazil: Writing of History, Historiographic Quarrels and Readings of the Past in the nineteenth century

\title{
Alphonse de Beauchamp e a história do Brasil: escrita da história, querelas historiográficas e leituras do passado no oitocentos'
}

\author{
Bruno Franco Medeiros \\ Mestrando em História pela \\ Universidade de São Paulo (FFLCH / \\ USP - São Paulo / Brasil) \\ e-mail: bfrancomedeiros@gmail.com
}

\begin{abstract}
Resumo
Este informe de pesquisa apresenta alguns apontamentos sobre a recepção de Alphonse de Beauchamp e sua Histoire du Brésil, publicada em Paris, em 1815, no contexto de elevação do Brasil à condição de Reino Unido de Portugal e Algarves. Acusado por Robert Southey de ter plagiado o primeiro volume da sua History of Brazil (1810), Beauchamp teve sua recepção na historiografia oitocentista brasileira marcada pela acusação de plágio, o que não foi de todo incomum em seu percurso intelectual também em França, onde ele foi alvo de polêmicas semelhantes. Nossa pesquisa procura elucidar quais eram as concepções de plágio correntes à época e como, à luz das transformações operadas no conceito de história, os diferentes interlocutores luso-brasileiros reagiram à obra deste autor. A permanência de referências pré-modernas do conceito de história paralela à emergência do conceito moderno contribuiu para uma série de querelas historiográficas, dentre elas, aquelas relacionadas ao plágio.
\end{abstract}

\begin{abstract}
This research presents some notes about Alphonse de Beauchamp's work reception and, specifically, his Histoire du Brésil, published in Paris in 1815, in the time of Brazil's elevation to United Kingdom of Portugal and Algarves. Accused by Robert Southey of plagiarism concerning his History of Brazil's first volume (1810), Beauchamp had his reception in the Brazilian historiography of nineteenth century marked by accusations of plagiarism. These accusations were also not rare in his intellectual career in France, where he was frequently named "plagiarist". Our research seeks to elucidate which were the conceptions of plagiarism in that time and how, from the transformations of the history concept, the different Luso-brazilians audiences reacted to Beauchamp's book. The permanency of pre-moderns references of the history concept parallel to the rise of the modern concept, contributed to a series of historiography debates, among other things, those related to the plagiarism.
\end{abstract}

\section{Palavras-chave}

modernidade, historiografia, Império do Brasil

\section{Keywords}

modernity, historiography, Brazilian Empire
Pesquisa de Mestrado financiada pela CAPES, sob orientação da Profa. Dra. Iris Kantor. 
2

Sobre as questões coloniais de Portugal e 0 Congresso de Viena, Cf. : ALEXANDRE, Valentim. Os sentidos do Império. Questão nacional e questão colonial na crise do Antigo Regime português. Porto: Edições Afrontamento, 1993. Em especial o capitulo intitulado " $\mathrm{Na}$ encruzilhada: o congresso de Viena", p.287-328.

BEAUCHAMP, Affonso de. Historia do Brazil desde o seu descobrimento em 1500 até 1810, vertida de Francez, e acrescentada de muitas notas do tradutor. Lisboa: Oficina de J. F. M. de Campos, 1817. p.12. Houve também uma tradução feita no Brasil em 1819 pelo Pe. Ignácio Felizardo Fortes.

BUESCU, Ana Isabel. Um mito das origens da nacionalidade: o milagre de Ourique. In: BETHENCOURT, Francisco; CURTO, Diogo Ramada (orgs.). A memória da nação. Lisboa: Sá da Costa, 1991.

Para uma maior compreensão da experiência do tempo como regeneração nesse periodo, Cf.: ARAUJO, Valdei Lopes de. A experiência do tempo: conceitos e narrativas na formação nacional do Brasil (1813-1845). São Paulo: Hucitec, 2008.

\section{Introdução}

Esta pesquisa tem como temática geral a investigação das transformações operadas no conceito de história entre fins do século XVIII e início do próximo. Seu ponto de partida e foco central é o estudo de um autor estrangeiro, Alphonse de Beauchamp (1767-1832), situado na tradição historiográfica francesa, mas que se preocupou com a escrita da história do Brasil. Propomos investigar o conjunto da obra de Beauchamp, dando especial atenção aos problemas relacionados à escrita da história nas obras dedicadas à história do Brasil - a Histoire du Brésil (1815) e L'Indépendance de l'Empire du Brésil, presentée aux monarques européenes (1824). Estas obras ocupam um importante lugar na formação das narrativas nacionais sobre o Brasil na primeira metade do século XIX, o que nos leva a uma análise das estruturas que ordenaram a composição desse tipo de narrativa. Além disso, o conceito de plágio assumiu um lugar central nesta pesquisa, devido às diversas acusações de plágio sofridas por Beauchamp durante seu percurso intelectual. A partir da leitura de algumas obras dedicadas à sistematização do plágio no início do século XIX, tentamos mostrar de que forma este conceito foi parte integrante da crise do caráter exemplar/modelar da escrita da história face ao surgimento do moderno conceito de história.

\section{Recepção e polêmica: Alphonse de Beauchamp e o mundo luso-brasileiro}

Com a vinda da Corte para o Brasil em 1808, não foram poucos os estrangeiros, além de portugueses e "brasileiros", que produziram narrativas históricas sobre o passado colonial motivados por esse novo campo de experiência histórica. Como muitos de sua época, Alphonse de Beauchamp (1767-1832) dedicou-se a escrever sobre a história do Brasil, apesar de nunca ter pisado em solo americano. Sua Histoire du Brésil vinha à luz em 1815, no mesmo ano em que na Europa discutia-se as redefinições geopolíticas do continente europeu no Congresso de Viena. ${ }^{2}$

Imediatamente, sua história começara a ser traduzida no ano de 1817 em Lisboa, com algumas interrupções até 1834. Traduzida por Desidério Marques Leão, essa tradução contou com o apoio do Príncipe do Brasil D. Pedro de Alcântara, sendo-Ihe dedicada. No prólogo, o tradutor chamou a atenção para alguns erros cometidos pelo historiador francês em sua história, principalmente por não ter sido uma testemunha ocular no teatro dos acontecimentos que ele narrava, sendo necessário, durante o trabalho de tradução, realizar alguns apontamentos de modo a chamar a atenção às passagens ambíguas e desenganadas da obra. Apesar disso, Marques Leão concluiu que não tinha que "acreditar a Obra, ela por si se recomenda; basta ser Historia de Portugal para ser lida com gosto" 3 . Certamente, o fato de Alphonse de Beauchamp iniciar o capítulo da sua Histoire du Brésil com uma breve história de Portugal a partir do ano de 1139 - ano da batalha no Campo de Ourique, lugar comum na historiografia portuguesa considerado as origens nacionais de Portugal ${ }^{4}$ - e terminar com a notícia do descobrimento do Brasil abriu caminhos para a compreensão da história do Brasil como regeneração de Portugal 5 .

Em 1826, José da Silva Lisboa (1756-1835), o Visconde de Cairu, fazia menção à Histoire du Brésil numa espécie de balanço historiográfico que abria a sua História dos principais sucessos politicos do Brasil. Comparando a obra de Alphonse de Beauchamp com a de Robert Southey (1774-1843), Cairu elogiou a obra de Beauchamp por ser mais concisa que a de Southey. 
LISBOA, José da Silva. Historia dos principaes successos politicos do Imperio do Brasil. Parte 1. Rio de Janeiro: Typographia Imperial e Nacional, 1826. p.19.

Sobre a polêmica entre Varnhagen e Abreu e Lima, Cf.: MATTOS, Selma Rinaldi. Para formar os brasileiros. 0 Compêndio da História do Brasil de Abreu e Lima e a expansão para dentro do Império do Brasil. Tese (Doutorado em História Social). Faculdade de Filosofia, Letras e Ciências Humanas, Universidade de São Paulo, São Paulo, 2007.

\section{8}

VARNHAGEN, Francisco Adolfo de. Primeiro Juizo. Submetido ao IHGB pelo seu sócio Francisco Adolfo de Varnhagen acerca do 'Compêndio de História do Brasil' pelo Sr. José Inácio de Abreu e Lima. Revista do Instituto Histórico e Geográfico Brasileiro, Rio de Janeiro, t. VI, p.63-64, 1844.

PIMENTA, João Paulo G.; ARAUJO, Valdei Lopes de. História (Brasil). In: FERES JR., João. (org.). Léxico da história dos conceitos políticos do Brasil. Belo Horizonte : Ed. UFMG, 2009. p.124.

10

BEAUCHAMP, Alphonse de. Histoire du Brésil, depuis sa découverte en 1500 jusqu'à 1810. Paris: Alexis Eymery, 1815. p.VIII-X.
Em seguida, classificou Beauchamp como "estrênuo e eloqüente advogado do Brasil" devido à apologia feita pelo francês a respeito da permanência de D. Pedro I no Brasil durante o processo de Independência. Recuperando uma passagem da obra de Beauchamp sobre a Independência do Brasil, Cairu citava Beauchamp: "Monarcas Europeus! Dizei o que devia fazer D. Pedro! Devia regressar a Portugal, e render-se à discrição dos Conselheiros de seu Pai? Se tal se resolvesse, terieis dezenove Republicas, e dezenove Bolivars de mais no Hemisfério d'América". Para Cairu, estas linhas equivaliam a volumes 6 .

$\mathrm{Na}$ década de 1840, o nome de Beauchamp foi recuperado em meio a uma polêmica protagonizada pelo general José Ignácio de Abreu e Lima (1794-1869) e Francisco Adolfo de Varnhagen (1816-1878), acerca de um juízo desfavorável feito por Varnhagen sobre o Compêndio da História do Brasil (1843) de Abreu e Lima, juizo publicado na Revista do Instituto Histórico e Geográfico Brasileiro em 1844 7. Varnhagen desqualificou a obra de Abreu e Lima devido ao fato de este último ter-se apoiado em grande parte na tradução da Histoire du Brésil de Beauchamp para compor o seu Compêndio. 0 que se vê no Juizo de Varnhagen, na verdade, é um severo ataque a Alphonse de Beauchamp. Varnhagen julgava que Abreu e Lima copiou Beauchamp, que por sua vez teria copiado Southey, além de dizer que Beauchamp "procura disfarçar o plágio, dá a algumas idéias novas formas, suprime outras, sacrifica muitas vezes a verdade histórica ao estilo fascinador, e por tanto, mais perigoso (...)" 8 . Devido à boa reputação da qual gozou na historiografia brasileira desde o século XIX, Varnhagen contribuiu em grande medida para o descrédito e ausência de Alphonse de Beauchamp na história da historiografia brasileira, na qual sempre fora lembrado como plagiário. A partir de uma análise mais detida sobre o conceito de plágio no início do século XIX pretendemos mostrar que, para além da acusação de furto de obras alheias, o conceito de plágio comportou outros significados.

\section{0 plágio e sua compreensão a partir das transformações operadas no conceito de história na passagem do século XVIII para o XIX} Quando publicou a Histoire du Brésil em 1815, Alphonse de Beauchamp disse que durante sete anos juntou material, ordenou e redigiu a sua história do Brasil, em meio à criação e publicação de outras obras de sua autoria. Segundo ele, estando dois volumes já prontos, poderia publicá-los, mas preferiu ser fiel ao seu plano primitivo de publicar uma histoire générale du Brésil, o que só veio a ser concretizado com o término do terceiro volume. A definição de história geral que encontramos em Beauchamp tem uma característica singular na história da historiografia: ela tem como meta a reunião, a somatória das várias histórias particulares escritas sobre o Brasil até então, diferente da história geral produzida por Varnhagen, a qual comportava outros significados 9 .

Beauchamp disse que, entre a escrita de um volume e outro, apareceu em Londres uma "compilação" sobre a História de Buenos Aires e do Brasil até 1640, cujo autor era Robert Southey. Segundo Beauchamp, sem oferecer nada de novo, Southey prometia para 1810 a publicação de um segundo volume que completaria os anais do Brasil. "Vã esperança", escreveu Beauchamp sobre a expectativa do volume prometido10. 0 segundo volume da History of Brazil só apareceria em 1817.

Com a publicação deste volume, Southey acusou Beauchamp de ter produzido sua obra a partir do primeiro volume de sua história, excetuando 
SOUTHEY, Robert. Preface. In: History of Brazil. Part the Second. London: Longman, 1817. p.VIIVIII. Segue a passagem no original: "The list of authorities which he has given is copied from my marginal references; the manuscripts which he pretends to quote are those in my possession, and only those which I had used in my first volume. The whole matter of his history is taken from that volume, as far as it would carry him, and from no other source; and in many places it is close translation. Care has been taken to disguise this plagiarism by transposing the matter as much as possible, and omitting all that relates to Paraguay, ..for M. Beauchamp is no novice in the art of plagiarism, as M. de Puissaye, and other of his countrymen, may bear witness." (Grifos meus).

\section{2}

BEAUCHAMP, Alphonse de. Histoire du Brésil, depuis sa découverte en 1500 jusqu'à 1810. Paris: Alexis Eymery, 1815. No original: Les érudits me reprocheront sans doute de n'avoir point hérissé les pages de cette histoire de notes, de citations et de comentaires. Je n'ai qu'une seule objection à leur opposer, et elle est sans réplique; c'est que malheureusement je ne suis point un érudit. J'aurais pu faciliment, et tout comme un autre, me donner le mérite d'un certain étalage d'érudition et de citations; mais ce petit charlatanisme m'aurait semblé ridicule et tout à fait indigne d'un écrivain qui fait profession de franchise et de loyauté. On peut d'ailleurs opposer au système des citations minutieuses l'autorité des historiens de l'antiquité, seuls modeles qu'avoue la saine critique, et l'exemple de plusieurs historiens modernes qui ont marche sur leurs traces. A quoi bon, par exemple, citer dans les mêmes pages des auteurs qu'il faut souvent concilier ou contredire, et dont la version a besoin d'être corrigée ou complétée par d'autres témoignages? Les mémoires sont à l'historien ce que leus couleurs sont au peintre [...].

\section{3}

ARNAULT, Antoine-Vincent. Du plagiat et des plagiaires. Revue de Paris. Paris: Le Vavasseur, 1830. p.193.

\section{4}

GRAFTON, Anthony. As origens trágicas da erudição moderna: pequeno tratado sobre a nota de rodapé. Campinas: Papirus, 1998.

\section{5}

HANSEN, João Adolfo. A sátira e o engenho. Gregório de Matos e a Bahia do século XVII. São Paulo: Companhia das Letras/Secretaria de Estado da Cultura, 1989. Em especial o primeiro capitulo, intitulado "Um nome por fazer". Cf. p.5 acima.

\section{6}

BOUZA, Fernando. Corre Manuscrito: uma historia cultural del siglo de oro. Madri: Marcial Pons, 2001. p.21-22.

17

GRAFTON, Anthony. Op.Cit. p.16. o capítulo introdutório sobre a história de Portugal e outro contendo a descrição geral do Brasil. Para o autor inglês,

a lista de autoridades as quais ele cita é copiada das minhas referências de margem; os manuscritos os quais ele alega citar estão sob minha posse, e somente aqueles que eu usei no meu primeiro volume. Toda a matéria de sua história é tomada a partir daquele volume [...]. M. Beauchamp não é novato na arte do plágio, como M. de Puissaye, e outros conterrâneos seus podem testemunhar [...].11

Ao explicar a forma como escreveu a sua história, Beauchamp já antecipava uma defesa sobre qualquer acusação que the fosse dirigida:

Os eruditos me reprovarão sem dúvida de não ter enchido as páginas desta história de notas, de citações e de comentários. Tenho apenas uma objeção a Ihes fazer, e esta é sem réplica; é que eu não sou um erudito. Poderia facilmente, como qualquer outro, me expor ao mérito de erudição e citações; mas esse pequeno charlatanismo me faria parecer ridículo e indigno de um escritor que faz profissão de franqueza e lealdade. Poderíamos opor ao sistema de citações minuciosas a autoridade dos historiadores da antiguidade, únicos modelos que confessam uma crítica sã, e o exemplo de muitos historiadores modernos que seguem os seus rastros. [...] As memórias são à história o que as cores são para o pintor. É somente pela sua combinação e fusão que o quadro da história que daí resulta forma uma composição completa e regular. ${ }^{12}$

A acusação de plágio por Southey se baseia na possivel apropriação dos fundos documentais de sua obra por Beauchamp: dos seus manuscritos e das suas referências de margem. Ao definir o plágio, num artigo publicado na Revue de Paris em 1830, Antoine-Vincent Arnault (1766-1834) disse que "o plágio não consiste no empréstimo das idéias de outro, mas no silêncio conservado neste empréstimo. Tomar emprestado não é roubar"13. Ao fim do prefácio da Histoire du Brésil, Beauchamp listou uma relação de 64 livros que ele utilizou na escrita de sua história, dentre os quais Southey foi citado. Portanto, não houve omissão sobre a utilização da obra do historiador inglês. É certo que existem passagens nas duas obras cujo paralelismo pode ter servido para nutrir ainda mais as acusações de plágio. De certa forma, ao menos desde a historiografia antiga e até mesmo em alguns casos no século XIX, encontramos diversos autores fazendo largo uso de textos sem usarem notas de rodapé, incluindo na construção do texto pequenas alterações para mostrar que o haviam feito daquele modo ${ }^{14}$. Uma história se constituía mais em termos de uma combinatória de elementos coletivizados - neste caso a junção de várias obras formando uma histoire générale du Brésil 15.

A questão relativa aos manuscritos traz consigo o problema da produção original dos documentos. Comparado ao texto impresso, que possui formas de produção e circulação rigorosamente reguladas durante o Antigo Regime, o texto manuscrito e sua circulação possuíram características que escaparam a determinados tipos de controle. Atualmente, seria ingênuo afirmar que um manuscrito é passivel de uma originalidade intocável, constituída de uma autoria indiscutivel, ao invés de perceber que na cópia manuscrita é possível reconhecer várias mãos e, por tanto, mais de um autor ${ }^{16}$. Quanto às referências de margem (ou notas de rodapé), elas estão ligadas, na época moderna, aos instrumentos de prova que se tornaram indispensáveis na constituição de uma história erudita ${ }^{17}$. Quando 
Gaëtan de Raxis de Flasan publicou uma Histoire de la Diplomatie Française entre 1808 e 1811. Beauchamp resenhou essa obra para a Gazette de France em dois artigos em 1812. No mesmo ano Flasan publicou um opúsculo intitulado Apologie de l'histoire de la diplomatie française, na qual refutava o que ele considerava as falsidades e erros cometidos por Beauchamp em sua resenha.

\section{9}

FLASAN, Gaëtan de Raxis de. Apologie de I'histoire de la diplomatie française. Paris: Debray, 1812.

\section{0}

GRAFTON, Anthony. As origens trágicas da erudição moderna: pequeno tratado sobre a nota de rodapé. Campinas: Papirus, 1998. p.36-38.

\section{1}

BLOCH, Marc. Apologia da história, ou ofício do historiador. Rio de Janeiro: Jorge Zahar Ed, 2001. Em especial o capítulo 3. BOURDÉ, Guy; MARTIN, Hervé. Les écoles historiques. Paris: Seuil, 1997. Em especial o capítulo 6.

22

BOURDÉ, Guy; MARTIN, Hervé. Op.Cit. p.128-130.

23

Retiro o termo "derrota" da erudição do livro clássico de Blandine Kriegel. La défaite de l'érudition. Paris: Quadrige/PUF, 1989.

24

GRAFTON, Anthony. Op.Cit. p.86.

25

BOURDÉ, Guy; MARTIN, Hervé. Op.Cit. p.140-141.
Gaëtan de Raxis Flasan (1760-1845) polemizou com Beauchamp em 181218, aquele dizia que o tipo mais comum da história escrita pelos antigos baseava-se na produção de um grande efeito, sem segui-la de provas (preuves, no original). Segundo Flasan, os antigos conheciam pouco aquilo que ele denominou de pièces officieles, que os historiadores modernos utilizavam a fim de produzir uma história mais confiável. Enquanto os historiadores antigos foram mestres em conceder exemplos, os historiadores modernos foram mestres no levantamento de provas e pièces officieles na construção de sua narrativa histórica ${ }^{19}$. Portanto, quando o historiador se profissionalizou no século XIX, ao citar documentos ele não fazia referência a modelos de história, mas às fontes 20 .

As notas de rodapé fazem parte das técnicas engendradas na formação da crítica e erudição histórica na época moderna. Na França, os nomes de Mabillon e Montfaucon são indiscutivelmente associados ao surgimento de um método crítico para a história ${ }^{21}$. No interior de uma historiografia oficial, a erudição não alcançou grandes proporções na França durante o século XVIII e início do XIX, apesar de nutrir uma importante tradição, mesmo que subterrânea ${ }^{22}$. Um dos fatores que ocasionaram a "derrota" da erudição 23 na França foi a grande importância atribuída à história política forjada no grand siècle, assentada no discurso elogioso e panegírico do rei. Também a história filosófica, desenvolvida pelos iluministas franceses, descartava qualquer tipo de minúcias. Voltaire fora um grande inimigo da erudição ao desprezar "a estéril ciência dos fatos e das datas" 24: mais preocupado em estudar os motivos e as paixões que guiavam as ações humanas, Voltaire escrevia história brevemente e sem encobrir sua narrativa de detalhes inúteis 25 .

As passagens que Alphonse de Beauchamp retirou da obra de Southey não foram citadas em inglês, mas vertidas para o francês, o que nos leva ao centro das discussões sobre tradução nesse período. No mesmo texto publicado na Revue de Paris, Arnault disse que
26

ARNAULT, Antoine-Vincent. Du plagiat et des plagiaires. Revue de Paris. Paris : Le Vavasseur, 1830. No original: "Quant au traducteur qui fait passer dans notre langue des idées, et à plus fort raison des ouvrages empruntés à une langue étranger, il y a entre lui et le plagiaire la différence du conquérant au voleur. Que faitil ? qu'importer dans la littérature nationale des trésors qui autrement n'existeraient pas pour elle? D'ailleurs les efforts par lesquels on fait passer dans une langue les beautés d'une autre langue ne donnent-ils pas au traducteur un droit de propriété sur l'ouvrage traduit?"

\section{7}

ANDERSON, Benedict. Nação e Consciência Nacional. São Paulo: Ática, 1989. p.46-56. SMITH, Anthony D. Invention and Imagination. Nationalism and Modernism. A critical survey of recent theories of nation and nationalism. New York: Routledge, 1998. p.135.

\section{8}

NODIER, Charles. Questions de littérature légale No original : "Définissons donc le plagiat proprement dit, l'action de tirer d'um auteur (particulièrement moderne et national, ce qui aggrave le délit) le fonds d'un ouvrage d'invention. " $p$. 17. (Grifo meu). quanto ao tradutor que fez passar em nossa língua as idéias e especialmente obras emprestadas de uma língua estrangeira, existe entre ele e o plagiário a diferença do conquistador ao ladrão. Que fez ele senão importar na literatura nacional os tesouros que de outro modo não existiriam para ela? Aliás, os esforços pelos quais se fez passar numa lingua as belezas de outra língua não dão eles ao tradutor um direito de propriedade sobre a obra traduzida? 26

Benedict Anderson apontou como uma das possiveis chaves para compreender as origens da consciência nacional a crescente importância das línguas vulgares durante a época moderna e sua disseminação a partir dos livros impressos, o que originou aquilo que Anthony Smith, considerando a obra de Anderson, chamou de print-comunities ${ }^{27}$. Quando definiu o conceito de plágio em 1812, em seu Questions de littérature légale, Charles Nodier (1780-1844) dizia: "Definimos, portanto o plágio propriamente dito, a ação de tirar de um autor (particularmente moderno e nacional, o que agrava o delito) o fundo de uma obra de invenção"28. Ao depararmo-nos com as opiniões de Arnault e Nodier, percebemos que o conceito de plágio também veio reforçar as fronteiras e limites das literaturas nacionais.

Alphonse de Beauchamp teria seu percurso intelectual marcado por freqüentes acusações de plágio. Um desses ataques veio novamente em 1822, quando publicou a biografia de Ali Pacha, logo após sua morte. Às 
29

BEAUCHAMP, Alphonse de. Vie d'Ali Pacha, Visir de Janina. Paris: Villet, 1822. p.7-8.
30

BEAUCHAMP, Alphonse de. Op.Cit. p.18-20. No original : « M. de Beauchamp, connu par sa prédilection pour l'histoire contemporaine, doit voir maintenant, par les attaques que lui ont attirées sa Vie d'Ali Pacha, combien il est épineux d'écrire la vie d'un tyran, et même d'un tyran étranger. (..) Avoir déjà écrit sur un sujet d'histoire, ne constitue pas le privilége de l'exploiter exclusivement. Les événemens publics appartiennent à tous les écrivains (...). Y avait-il une Vie d'Ali Pacha avant celle de M. de Beauchamp ? Non, il n'existait que des fragmens épars, des mémoires isolés, des relations incomplètes. Si puiser dans ces matériaux, pour les façonner et les arranger, c'est piller, M. de Beauchamp, qui a fait une Vie d'Ali Pacha, écrite avec chaleur, rapidité et clarté, est un plagiaire, à la manière de tous les historiens. " (Grifos meus)

31

BEAUCHAMP, Alphonse de. 0p.Cit. p.20-22.

32

VOUILLOT, Bernard. La Révolution et I'Empire : une nouvelle réglementation. In : CHARTIER, Roger ; MARTIN, H.-J. (orgs.). Histoire de l'édition française. Tome II. Le livre triomphant (1660-1830). Paris : Promodis, 1984.

33

CHARTIER, Roger. Property \& Privilege in the Republic of Letters. Daedalus, vol.131, n.2, p.62, On Intellectual Property (Spring, 2002). vésperas da publicação, Beauchamp tomou conhecimento que François Pouqueville (1770-1838) reuniria os estudos esparsos de sua viagem à Grécia para escrever uma vida de Ali Pacha. Para Beauchamp, "(...) um tipo habitual de pressentir as intrigas literárias, como as intrigas politicas, me fizeram suspeitar que meu livro seria atacado em um certo jornal" 29 . Suas suspeitas foram confirmadas no dia 23 de junho de 1822, quando o periódico Courrier Français o denunciou como um plagiador, um copista, que formou todo o corpo de sua obra a partir da obra de Pouqueville, Viagem à Grécia, publicada em Paris entre 1820 e 1822. Dois dias depois, o periódico Drapeau Blanc repetia a mesma acusação. Beauchamp tentou replicar as acusações numa resposta que seria publicada nos dois periódicos, porém sem sucesso. Todavia, em 4 de julho, o periódico La Quotidienne fez apologia da obra de Alphonse de Beauchamp nesses termos:

(...) Ter já escrito sobre um assunto de história não constitui privilégio de exploração exclusiva. Os eventos públicos pertencem a todos os escritores (...). Havia uma Vie d'Ali Pacha antes daquela de M. de Beauchamp? Não, existiam somente fragmentos esparsos, memórias isoladas, relações incompletas. Se tomar esses materiais, para Ihes elaborar e arranjar, é roubar, M. de Beauchamp, que fez uma Vie d'Ali Pacha escrita com calor, rapidez e clareza, é um plagiário à maneira de todos os historiadores. 30

Beauchamp pergunta se poderia ser considerado um plagiário por ter utilizado algumas passagens relativas às relações politicas entre Ali Pacha e François Pouqueville, já que todas as citações referentes à obra de Pouqueville na sua Vie de Ali Pacha estavam entre aspas e traziam a indicação da obra de onde foram tiradas. "Isto é uma fraude? Citar é roubar?", questionou Beauchamp. A acusação seria infundada, pois, segundo Beauchamp, não haveria uma só página na sua obra, excetuando as citações, que não mostrava seu estilo e seu método, que consistia em "incorporar, conciliar ou esclarecer, seja de versões diferentes, seja de relações apaixonadas ou contraditórias". 31

0 direito de propriedade autoral vinha se regularizando tanto em Inglaterra quanto em França desde o início da época moderna. Na França, da Revolução à Restauração, as leis que regulavam os direitos de impressão e propriedade sofreram diversas alterações durante esse periodo 32 . Envolvendo livreiros, impressores e autores, a discussão sobre o direito de propriedade foi ganhando cada vez mais força. Em meados do século XVIII Diderot já havia evocado uma nova imagem do homem de letras: aquele que vivia de sua pena ${ }^{33}$. Muitos autores tentaram defender seu direito de propriedade autoral baseando-se nesse pressuposto, dentre eles o livreiro parisiense Louis-Marie Proudhomme (1752-1830). Quando publicou o Dictionnaire universel historique em 1811, obra que ele tinha adquirido o direito de impressão, Proudhomme polemizou com os irmãos Louis-Gabriel Michaud (1773-1858) e Joseph-François Michaud (1767-1839), os quais publicaram sua Biographie Universel concomitante ao Dictionnaire. Para Proudhomme, a Biographie não passava de uma cópia do Dictionnaire. Para defender sua publicação, Proudhomme recuperou o papel do homem de letras descrito por Diderot:

Quando imitamos as produções de um autor, cometemos contra ele o crime de roubo, porque the roubamos o fruto de suas noites sem dormir e de seus trabalhos. (Répertoire du Jurisprudence). 
PROUDHOMME, Louis. De la propriété littéraire ou les contrefacteurs et les plagiaires démasqués. Paris: Prudhomme Fils, 1811. p.1.

35

lbidem. p.42

36

MILLIN, Aubin Louis. Dictionnaire des BeauxArts. Tome II. Paris : Desray, 1806. p.166-7.

37

Encyclopédie, ou Dictionnaire Raisonné des Sciences, des Arts et des Métiers. Par une société de gens de lettres. Tome Dix-Huitième. Berne et Lausanne: Sociétés Typographiques. MDCCLXXXII. p.372. (Grifos meus).

38

KOSELLECK, Reinhart. Historia Magistra Vitae: sobre a dissolução do topos na história moderna em movimento. In: _._. Futuro Passado. Contribuição à semântica dos tempos históricos. Rio de Janeiro: Contraponto: Ed.UERJ, 2005.

39

As implicações e conseqüências da Revolução Francesa para a compreensão de uma nova experiência do tempo e de um novo regime de historicidade foi descrita por François Hartog em sua análise sobre o Essai historique (1797) e o Voyage em Amérique (1827), ambos de Chateaubriand. Cf. HARTOG, François. Régimes d' Historicité. Présentisme et expériences du temps. Paris: Seuil, 2003.
Desmascarar os copiadores e plagiários é render à sociedade um serviço importante. (...) Não é somente minha propriedade que defendo hoje, e sim também aquela de qualquer pai de familia e honestos capitalistas, que, conhecendo minha honestidade, meu zelo, minha economia, minha responsabilidade, não opõem êxito a me confiar somas consideráveis para realizar uma empresa bibliográfica de uma utilidade evidente. $^{34}$

Coincidência ou não, Alphonse de Beauchamp fora um dos autores que contribuiram para a Biographie Universel dos irmãos Michaud. Joseph François Michaud era editor-chefe do periódico La Quotidienne, quando Beauchamp foi defendido da acusação de plágio da obra de François Pouqueville em 1822. A resposta dos irmãos Michaud a Prudhomme em 1811 assemelha-se à defesa feita a Beauchamp anos depois: "uma obra de história não pode ser vista como uma cópia; ela relata fatos, eventos conhecidos, que pertencem a todos" 35 .

\section{Apontamentos finais}

Ao concluir o verbete imitação do seu Dictionnaire des Beaux-Arts (1806), Aubin Louis Millin (1759-1818) disse que somente ao imitar os "grandes autores" um autor alcançaria sua própria identidade e que a arte só alcançou seu progresso devido à imitação de um autor por outro: sem imitação ela permaneceria sempre na sua infância e barbárie ${ }^{36}$. Na Encyclopédie, o verbete imitação foi definido da seguinte forma:

Imitação.s.f. Poésie; Reth. Pode-se defini-la como o empréstimo de imagens, de pensamentos, de sentimentos, que se busca nos escritos de algum autor, e sobre os quais se faz uso, seja diferente, seja aproximando, seja enriquecendo sobre 0 original. Nada é mais permitido do que usar as obras que estão entre as mãos de todo mundo. 37

Até meados do século XVIII, a fórmula ciceroniana da Historia Magistra Vitae havia guiado não somente como os historiadores compreendiam o seu objeto - o passado - mas também como o representavam. A história era considerada um cadinho repleto de modelos e exemplos a serem seguidos e imitados. Isso era também uma função da escrita da história - recorrer a exemplos de historiadores antigos para imitar o seu modo de escrita da história. 0 caráter de originalidade de um evento ou mesmo de uma obra não era possivel, pois a compreensão do tempo engendrada pela Historia Magistra Vitae encerrava-se em si mesma. Essa proposição só se tornaria insustentável quando a história destituiu-se do cargo de mestra da vida para tornar-se mestra de si. A partir de então, o horizonte de expectativa não se nutria mais a partir de um passado imutável, mas sim em direção a um futuro aberto ${ }^{38}$. A sensação de aceleração do tempo, maximizada pela Revolução Francesa, contribuiu para a crise da exemplaridade em história: os paralelismos históricos a partir de então se esgotaram ${ }^{39}$. Desde então, grande parte do significado do conceito de imitação, antes considerado edificante e recomendável, migrou para o conceito de plágio, então considerado negativo e reprovável. Neste contexto, os autores que ainda se baseavam exclusivamente na imitação dos cânones historiográficos para escrever sua história acabaram sofrendo um veto crítico, considerados plagiadores, como foi o caso de Alphonse de Beauchamp.

Encher as páginas de sua história de citações, comentários e notas, significou para Beauchamp ser um erudito. Procedendo de forma diferente, ele recusou a erudição. Um dos maiores entraves encontrados pela 
40

KRIEGEL, Blandine. La défaite de l'érudition. Paris: Quadrige/PUF, 1989. POCOCK, J. G. A. The politics of scholarship in French and English Enlightenment. In:_. Barbarism and Religion. The Enlightenment of Edward Gibbon, 1737-1764. Cambridge: CUP, 1999. p.137-151.

41

MOMIGLIANO, Arnaldo. L'Histoire Ancienne et l'Antiquaire. In__. Problèmes d'historiographie ancienne et moderne. Paris: Gallimard, 1983. p.277.

\section{2}

VOLTAIRE. Cartas Filosóficas. 1756. 0 contexto dessa citação é dado por Ginzburg, quando este mostrou as referências de Swift em Voltaire. Cf. GINZBURG, Carlo. Tolerância e Comércio - Auerbach lê Voltaire. In: _. O fio e os rastros. Verdade, mentira, ficção. São Paulo: Companhia das Letras, 2007. história erudita na constituição da historiografia francesa no século XVIII e início do século XIX foi a importância conferida à história filosófica. Na França, quando os historiadores filósofos começaram a atacar a erudição, o prestígio dos antiquários e dos historiadores eruditos começou a ser diminuido. Apesar de reconhecerem o trabalho crítico dos eruditos, os historiadores filósofos não sentiam necessidade de incluir detalhes minuciosos em suas pesquisas 40. Segundo Arnaldo Momigliano, o tema da civilização se tornou o tema central da história filosófica, e a história politica Ihe foi subordinada ${ }^{41}$. Alphonse de Beauchamp, ao recusar a erudição, seguia o caminho traçado pelos historiadores filósofos do século XVIII. Um destes historiadores defendeu o uso da imitação, e Beauchamp, que certamente o leu, levou a cabo o que este historiador havia dito:

Portanto, quase tudo é imitação. A idéia das Cartas Persas é tirada da idéia do Espião turco. Boiardo imitou Pulci, Ariosto imitou Boiardo. Os espíritos mais originais tomam empréstimos uns dos outros. (...) Acontece com os livros a mesma coisa que com o fogo em nossos lares; vamos buscar fogo no vizinho, acendemos o nosso, passamo-lo a outros, e ele pertence a todos 42 .

Seu autor: Voltaire. 